\title{
Distribution and Pollution Assessment of Heavy Metals in Beidaihe Near-Shore Marine Sediments
}

\author{
Hongwei Liu, Zhen Ma \\ Tianjin Center, China Geological Survey, Tianjin, China \\ Email: liuhenry022@163.com,61346723@qq.com
}

Received 1 July 2015; accepted 10 December 2015; published 17 December 2015

\begin{abstract}
The concentrations of heavy metals, $\mathrm{Cd}, \mathrm{Hg}, \mathrm{Pb}, \mathrm{Cu}$ and $\mathrm{As}$ in marine sediments from 138 sites located in the Beidaihe near-shore area of Bohai bay, were analyzed to find out the distribution characteristics of these heavy metals. Potential Ecological Risk index were adopted to assess the heavy metals contamination, and the assessment results indicated that the content of heavy metals in this area is in a low to moderate level, while high values were found in the southwest and northeast region, and the value in the middle region is comparatively low. The high pollution hazard sites were close to the Renzaohe estuary and Shihe estuary and the high risk is mainly led by Hg.
\end{abstract}

\section{Keywords}

Heavy Metals, Marine Sediments, Distribution, Contamination Assessment, Beidaihe

\section{Introduction}

The study area is located at Beidaihe near-shore area of Bohai Bay, which belongs to Qinhuangdao city, Hebei Province. It is a famous holiday resorts and important Aquatic products culture zones in Bohai Bay. There are rivers running into the Bohai Bay, including Shihe, Tanghe, Daihe, Yanghe, Renzaohe, Dapuhe, etc. which bring various rich nutrients to the shore, together with pollutants emitted from land. The Beidaihe near-shore area, with shallow water depth and smooth currents, is conducive to various types of pollutants accumulation in the sediment. Due to the long time residual characteristic, easily enrichment feature and huge repairable difficulty, Heavy metals are likely to be the most important pollutants in marine sediment, which are also easily to be transferred along the food chain and proved having badly negative impact on aquatic life and human health [1]. Based on the analysis of the distribution characteristics of heavy metals in surface sediments, contamination situation of heavy metal is well assessed in order to provide basic reference data for Beidaihe near-shore marine environmental protection.

\section{Sample Collection and Test}

One hundred and thirty eight un-disturbing samples were collected by Julong-180 drilling rig from sediments in

How to cite this paper: Liu, H.W. and Ma, Z. (2015) Distribution and Pollution Assessment of Heavy Metals in Beidaihe Near-Shore Marine Sediments. Journal of Materials Science and Chemical Engineering, 3, 1-7. 
Beidaihe near-shore area ranged between $119^{\circ} 20^{\prime} \mathrm{E}-119^{\circ} 50^{\prime} \mathrm{E}$ and $39^{\circ} 40^{\prime} \mathrm{N}-40^{\circ} 00^{\prime} \mathrm{N}$ in July, 2011 (Figure 1). Surface sediments were sampled in length of ten centimeter in any site as soon as profiles sediments which were collected in interval scale of half a meter vertically. Profile I, composed of drillings 2\#, 3\#, 4\# and 5\#, is located in Renzaohe estuary. Profile II, composed of drillings 11\#, 25\#, 24\#, 29\# and 27\#, is located in middle position of the research area. And profile III containing drillings 17\#, 16\#, 19\# and 15\# is located in Shihe estuary. The depth of these drillings is in the rage of 3 - 5 meters. Sediment samples were stored in accordance with the relevant provisions in Part 3 of GB/T 12763.3-2007 of "Specifications for Marine Monitoring”. Sample testing, with $\mathrm{Cu}, \mathrm{As}, \mathrm{Pb}, \mathrm{Hg}$ and $\mathrm{Cd}$, was completed by the Tianjin Mineral Resource Supervision Testing Center.

\section{Methods}

Hakanson [2] (1980) proposed Potential Ecological Risk index $\left(i_{r}\right)$ of Heavy metals in sediments to assess the potential ecological risk raised by heavy metals. The index reflects the environment sensitivity to heavy metals [3] (Rubio, 2000). According to this approach, the potential ecological risk index of the heavy metal $i$ is displayed as $E_{r}^{i}$. And the potential ecological risk index of a variety of heavy metals is calculated as follows (Equations (1)-(3)):

$$
\begin{gathered}
E_{r}^{i}=T_{r}^{i} C_{f}^{i} \\
C_{f}^{i}=C_{s}^{i} / C_{n}^{i} \\
i_{r}=\sum_{i=1}^{n} E_{r}^{i}=\sum_{i=1}^{n} T_{r}^{i} C_{f}^{i}=\sum_{i=1}^{n} T_{r}^{i} C_{s}^{i} / C_{n}^{i}
\end{gathered}
$$

where $T_{i}^{r}$ is the toxicity coefficient of the heavy metal $i$, which reflects the toxic level and the biological sensitivity raised by heavy metal $i$; $C_{f}^{i}$ is the enrichment factor; $C_{s}^{i}$ is the measured concentration; $C_{n}^{i}$ is the reference concentration.

Based on the research results from Hakanson [2] (1980), Li [4] (1994), Chen [5] (2008), Ye [6] (2008), Gan [1] (2010) and Luo [7] (2010), the toxicity coefficients of Cd, Hg, Pb, Cu and As is set up with 30, 40, 5, 5 and 10 respectively. Hakanson (1980) divided the potential ecological risk index into four levels (Table 1).

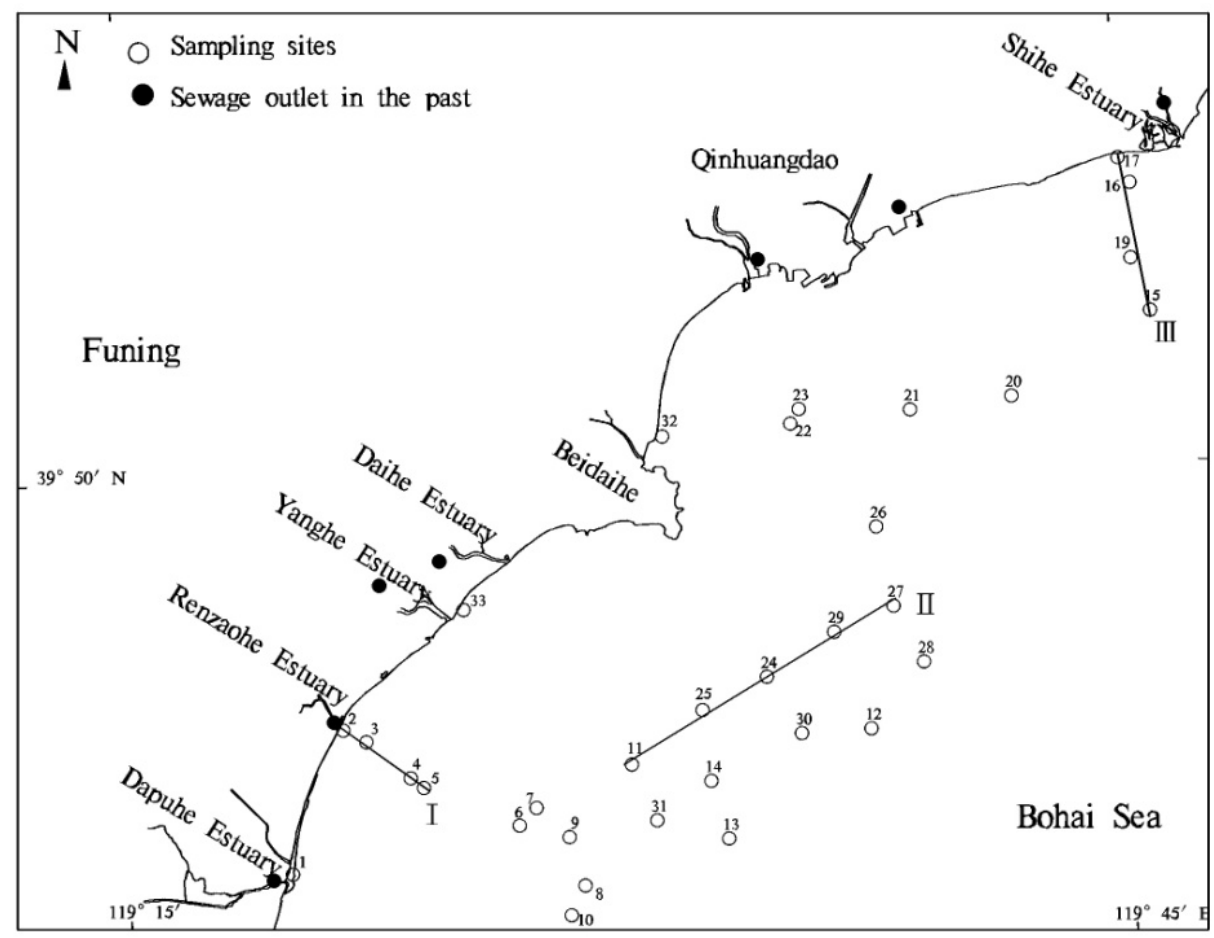

Figure 1. Location of surface sediment sampling sites in Beidaihe near-shore area. 
Table 1. The classification of the potential ecological risk of heavy metals.

\begin{tabular}{|c|c|c|c|c|c|}
\hline \multicolumn{6}{|c|}{ Class } \\
\hline & 1 & 2 & 3 & 4 & 5 \\
\hline$E_{r}^{i}$ & $(0,40)$ & {$[40,80)$} & {$[80,160)$} & {$[160,320)$} & {$[320,+\infty)$} \\
\hline$i_{r}$ & $\begin{array}{c}(0,75) \\
{[75,150)}\end{array}$ & $\begin{array}{l}{[150,225) ;} \\
{[225,300)}\end{array}$ & $\begin{array}{l}{[300,450) ;} \\
{[450,600)}\end{array}$ & {$[600,+\infty)$} & \\
\hline Level & Nile to very low; low & $\begin{array}{l}\text { Lower-moderate; } \\
\text { higher-moderate }\end{array}$ & High; very high & Extremely high & Ultra high \\
\hline
\end{tabular}

\section{Analysis and Assessment}

\subsection{Distribution Characteristic of Heavy Metals}

(1) Distribution characteristic in surface sediments

The general level of heavy metal content is low in sediments. Table 2 clearly shows five different statistic features of heavy metal content in surface sediments, including concentration range, mean, median, root-meansquare deviation and coefficient of variation.

$\mathrm{Cu}$ concentration looks more apparent at 31st and 16th sites while the content of As is more heavy at 3rd and 31st sites and value of $\mathrm{Pb}$ is more serious at 20th, 15th and 23rd sites (Figure 2). Whereas the other two heavy metals pollutions, $\mathrm{Hg}$ and $\mathrm{Cd}$, are serious at 22nd and 3rd sites, and 15th and 6th sties respectively. According to the mean value, the $\mathrm{Hg}$ concentration is highest while $\mathrm{Cu}$ concentration is the second highest among all these five heavy metals.

Concentrations of $\mathrm{Cu}, \mathrm{Pb}, \mathrm{Hg}$ and $\mathrm{Cd}$, with the highest value in near-shore of Renzaohe estuary and urban inshore area of Qinghuangdao, have a trend of higher from near-shore to sea, while As has a trend of lower (Figure 2).

Except that the coefficient of variation of $\mathrm{Cu}(73 \%)$ is more than $50 \%$, other four kinds of heavy metal coefficient of variations are all smaller, indicating that there is no obvious content distribution difference throughout the study area (Table 2).

(2) Distribution characteristic in profiles sediments

The concentration of $\mathrm{Cu}$ varies in range of $6.59-59.35 \mathrm{mg} / \mathrm{kg}$, with mean value of $21.81 \mathrm{mg} / \mathrm{kg}$, while As varies in range of $1.33-17.13 \mathrm{mg} / \mathrm{kg}$ with mean value of $7.30 \mathrm{mg} / \mathrm{kg}$ and the content of $\mathrm{Pb}$ varies in range of 6.38 - $41.32 \mathrm{mg} / \mathrm{kg}$, with mean value of $20.62 \mathrm{mg} / \mathrm{kg}$. At the same time, the concentration of $\mathrm{Hg}$ varies in range of $0.013-0.087 \mathrm{mg} / \mathrm{kg}$ with mean value of 0.037 when the concentration of Cd whose mean value is 0.089 varies in range of $0.041-0.335 \mathrm{mg} / \mathrm{kg}$. Compared with background values, the Hg pollution is most serious while $\mathrm{Cu}$ pollution is the second most serious among all these five heavy metals.

In profile I (Figure 3 and Figure 4), the concentration of Cu varies in range of $7.02-37.90 \mathrm{mg} / \mathrm{kg}$, with mean value of $23.63 \mathrm{mg} / \mathrm{kg}$, while As varies from 4.22 to $17.13 \mathrm{mg} / \mathrm{kg}$ with mean value of $9.11 \mathrm{mg} / \mathrm{kg}$; The concentration of $\mathrm{Pb}$ varies in range of $7.52-38.30 \mathrm{mg} / \mathrm{kg}$, with mean value of $23.39 \mathrm{mg} / \mathrm{kg}$, when $\mathrm{Hg}$ varies in range of $0.020-0.072 \mathrm{mg} / \mathrm{kg}$ with mean value is $0.037 \mathrm{mg} / \mathrm{kg}$; and the concentration of Cd whose mean value is 0.089 varies from $0.044-0.204 \mathrm{mg} / \mathrm{kg}$. Samples with highest concentration of $\mathrm{Hg}$ and $\mathrm{Cu}$ are located at 4th drilling. Concentration of $\mathrm{Hg}$ has a trend of lower from up-section of 3rd drilling and down-section of 4th drilling to around, and $\mathrm{Cu}$ has an extra higher value in up-section of 5th drilling.

In profile II (Figure 5 and Figure 6), the concentration of $\mathrm{Cu}$ varies in range of $6.59-34.43 \mathrm{mg} / \mathrm{kg}$, with mean value of $15.85 \mathrm{mg} / \mathrm{kg}$, while As varies from 1.33 to $11.10 \mathrm{mg} / \mathrm{kg}$ with mean value of $5.47 \mathrm{mg} / \mathrm{kg}$; The concentration of $\mathrm{Pb}$ varies in range of $6.38-34.20 \mathrm{mg} / \mathrm{kg}$, with mean value of $15.42 \mathrm{mg} / \mathrm{kg}$, when $\mathrm{Hg}$ varies in range of $0.013-0.087 \mathrm{mg} / \mathrm{kg}$ with mean value is $0.036 \mathrm{mg} / \mathrm{kg}$; and the concentration of $\mathrm{Cd}$, mean value of 0.072 , varies in range of $0.041-0.163 \mathrm{mg} / \mathrm{kg}$. Samples with highest concentration of $\mathrm{Hg}$ and $\mathrm{Cu}$ are located at the bottom of 11th drilling. Concentration of $\mathrm{Hg}$ has a trend of lower from down-section of 11th and 24th drillings to around, and $\mathrm{Cu}$ has an extra higher value in the top of 29th drilling.

In profile III (Figure 7 and Figure 8), the concentration of $\mathrm{Cu}$ varies in range of $8.28-59.35 \mathrm{mg} / \mathrm{kg}$, with mean value of $8.84 \mathrm{mg} / \mathrm{kg}$, when As varies in range of $3.65-15.93 \mathrm{mg} / \mathrm{kg}$ with mean value of $7.26 \mathrm{mg} / \mathrm{kg}$; The concentration of $\mathrm{Pb}$ varies from $7.85-41.32 \mathrm{mg} / \mathrm{kg}$, with mean value of $22.48 \mathrm{mg} / \mathrm{kg}$, while $\mathrm{Hg}$ varies in range 

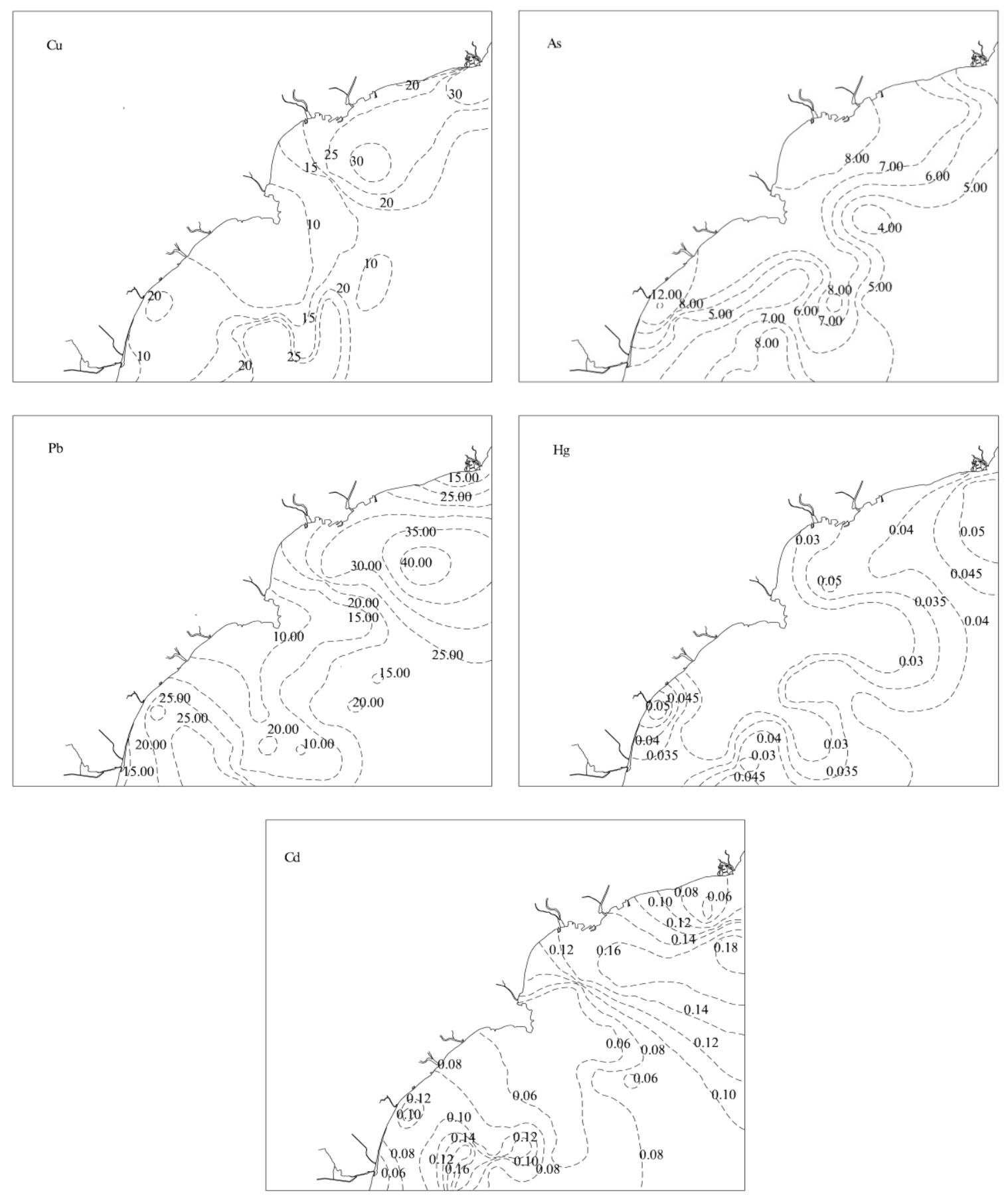

Figure 2. Distribution of the heavy medals in surface sediments [mg/kg].

Table 2. The content of the heavy metal in surface sediments [mg/kg].

\begin{tabular}{cccccc}
\hline Statistic feature & $\mathrm{Cu}$ & $\mathrm{As}$ & $\mathrm{Pb}$ & $\mathrm{Hg}$ & $\mathrm{Cd}$ \\
\hline Range & $5.03-66.26$ & $2.42-13.52$ & $7.85-45.17$ & $0.016-0.06$ & $0.047-0.186$ \\
Mean & 18.90 & 6.70 & 19.93 & 0.04 & 0.09 \\
Median & 13.69 & 6.50 & 18.88 & 0.04 & 0.07 \\
Root-mean-square deviation & 13.76 & 2.15 & 9.35 & 0.01 & 0.04 \\
Coefficientof variation & 0.73 & 0.32 & 0.47 & 0.32 & 0.48 \\
\hline
\end{tabular}




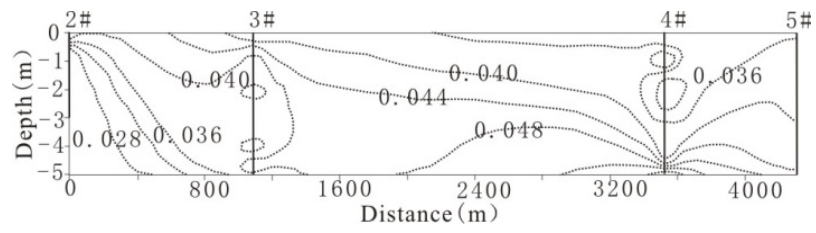

Figure 3. Distribution of the Hg in I-profile sediments [mg/kg].

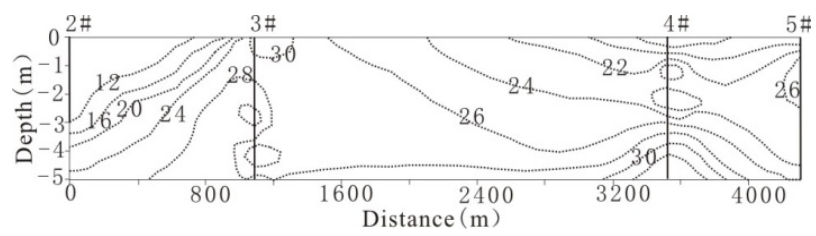

Figure 4. Distribution of the $\mathrm{Cu}$ in I-profile sediments [mg/kg].

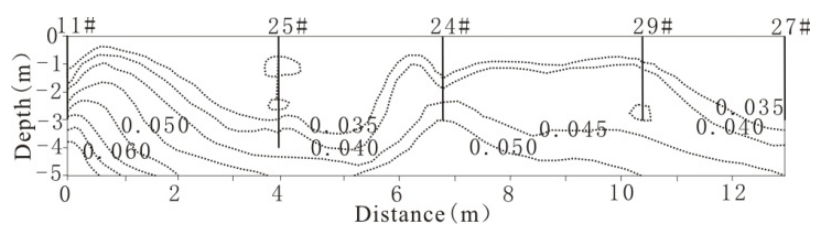

Figure 5. Distribution of the Hg in II-profile sediments [mg/kg].

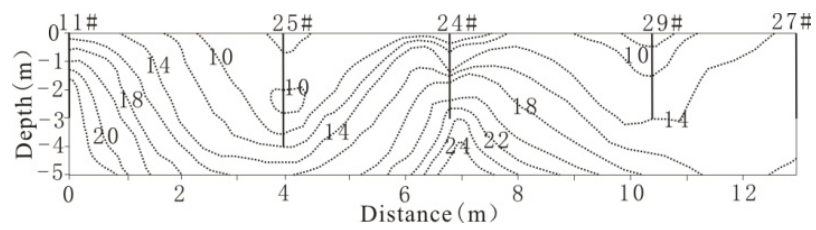

Figure 6. Distribution of the $\mathrm{Cu}$ in II-profile sediments [mg/kg].

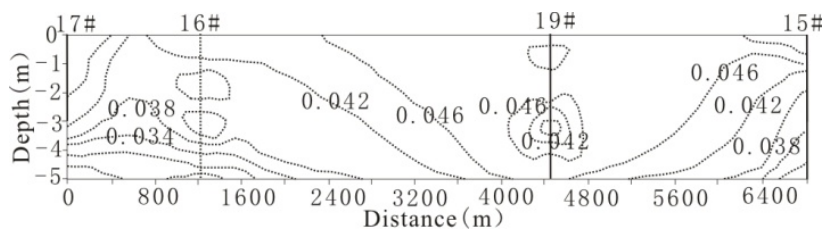

Figure 7. Distribution of the Hg in III-profile sediments [mg/kg].

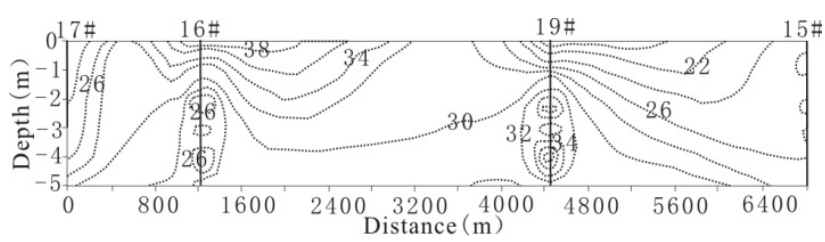

Figure 8. Distribution of the $\mathrm{Cu}$ in III-profile sediments [mg/kg].

of $0.021-0.083 \mathrm{mg} / \mathrm{kg}$ with mean value of $0.039 \mathrm{mg} / \mathrm{kg}$; and the concentration of Cd whose mean value is 0.104 varies in range of $0.053-0.335 \mathrm{mg} / \mathrm{kg}$. Samples with highest concentration of $\mathrm{Hg}$ and $\mathrm{Cu}$ are located at the top and middle of 16th drilling. Concentration of $\mathrm{Hg}$ has a trend of lower from up-section of 16th drilling and middle-section of 19th drilling to around as soon as $\mathrm{Cu}$.

\subsection{Pollution Assessment of Heavy Metals}

(1) Assessment result in surface sediments 
In the view of all the sample sites(Figure 1, Figure 9), the indexes of potential ecological risk ( $\left.E_{r}^{i}\right)$ of heavy metals are generally less than 40 except the risk index of Cd in sites 3rd, 6th, 15th, 20th, 21st, 23rd and 31st and the data of $\mathrm{Hg}$ at all sites are above 40 . It indicates that the potential ecological risk of heavy metals, $\mathrm{Cd}, \mathrm{As}, \mathrm{Cu}$ and $\mathrm{Pb}$, is comparatively low. However, the risk of $\mathrm{Hg}$ is at the moderate level in this region, therefore $\mathrm{Hg}$ is undoubtedly the main potential ecological risk pollutant.

The potential ecological risk $\left(i_{r}\right)$ of each site in the study area is below 250, which is at the range of low to moderate potential ecological risk level. The sites near to the Renzaohe estuary, Shihe estuary and Qinhuangdao City inshore area are with comparatively high risk. The 3rd site at the south area has the highest potential risk with the index 240.60. Combined with the characteristic of heavy metal distribution in this site, the high risk is led by Hg.

(2) Assessment result in profiles sediments

From the result of the single element (Figures 10-12), the index of $\mathrm{Cu}$ varies in range of 2.48 - 22.35, with mean value of 8.24 , while As varies in range of $1.82-23.43$ with mean value of $10.02 \mathrm{mg} / \mathrm{kg}$ and index of $\mathrm{Pb}$

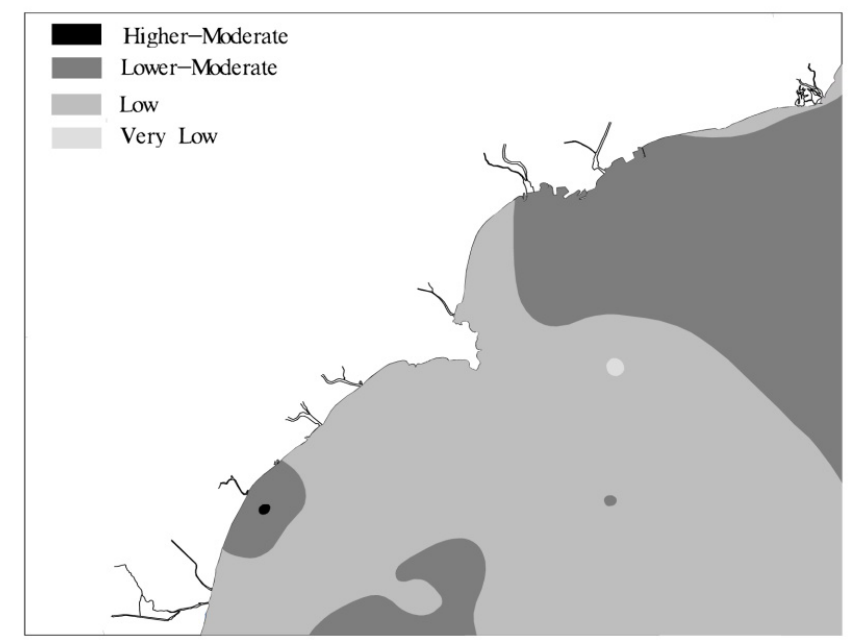

Figure 9. Assessment result based on $i_{r}$ in surface sediments.

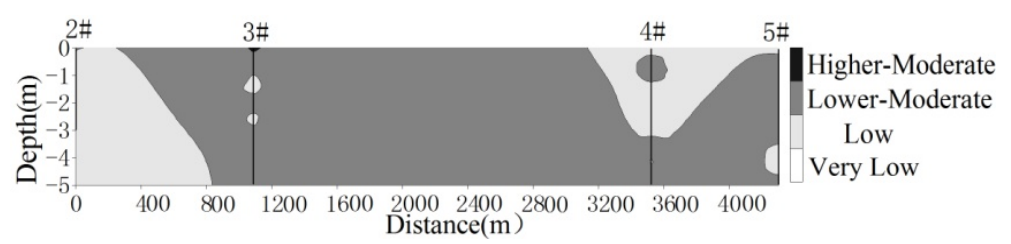

Figure 10. Assessment result based on $i_{r}$ in I-profile sediments.

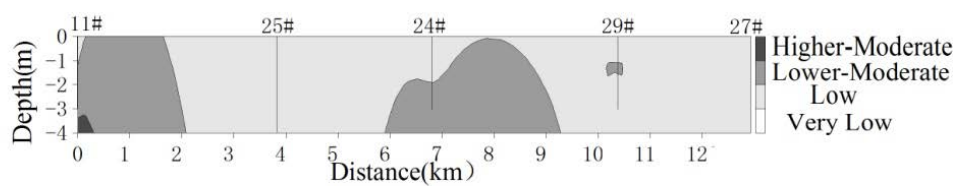

Figure 11. Assessment result based on $i_{r}$ in II-profile sediments.

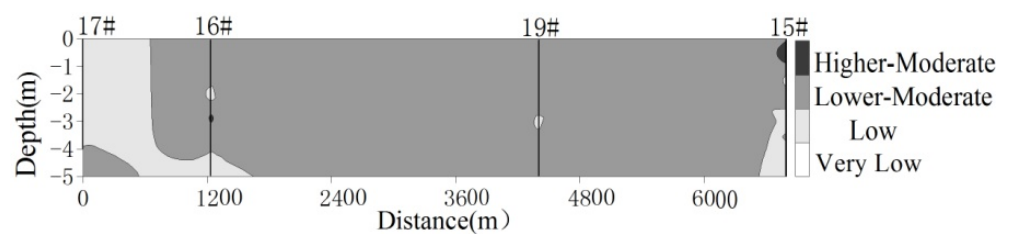

Figure 12. Assessment result based on $i_{r}$ in III-profile sediments. 
ranged from 1.63 to 10.57 , with mean value of 5.27. Whereas the other two heavy metals pollutions, $\mathrm{Hg}$ and $\mathrm{Cd}$, are in range of 33.10 - 221.51 (mean of 94.74) and 13.67 - 111.67 (mean of 29.72) respectively. Incontrovertibly, Hg pollution is most serious among these five heavy metals.

The indexes of potential ecological risk in profiles, with mean value of 147.99 and highest value of 288.40, indicate the heavy metals risk is in a low to higher-moderate level.

The $i_{r}$ of profile I and profile III indicate that the heavy metals risks, in majority of samples, are in lowmoderate levels (Figure 10, Figure 12). According to the low value of $i_{r}$, the risk level in profile II is demonstrated low except the contamination in bottom of left-section is at high-moderate level (Figure 11).

\section{Conclusions}

Results show that the contents of these five heavy metals are lower at the inshore area of Beidaihe and increase along the coastal lines. The distribution of As is different from others whose peak value lied at the inshore area, which is probably caused by the dissimilar sources. The average contents of $\mathrm{Hg}$ and $\mathrm{Cu}$ are comparatively higher than other metals.

Based on the assessment result of Potential Ecological Risk, pollution of heavy metals is in a low to moderate level in this area. Those sites nearing to Renzaohe estuary, Shihe estuary and central urban inshore zone are with higher risk comparatively.

\section{Acknowledgements}

This work was financially supported by the Geological Environment Investigation and Assessment in Laizhou Bay Area (12120113003800) and Comparative Research of Groundwater Management in the Coastal Areas in Southeast Asia (RETA 6498).

\section{References}

[1] Gan, H.Y., Liang, K. and Zheng, Z.C. (2010) Background Value, Contamination Assessment and Zoning of Heavy Metals in Sediments of the Pearlhe Estuary. Earth and Environment, 38, 344-350.

[2] Hakanson, L. (1980) Ecological Risk Index for Aquatic Pollution Control. A Sedimentological Approach. Water Research, 14, 975-1001. http://dx.doi.org/10.1016/0043-1354(80)90143-8

[3] Rubio, B., Nombela, M.A. and Vilas, F. (2000) Geochemistry of Major and Trace Elements in Sediments of the Ria de Vigo (NW Spain): An Assessment of Metal Pollution. Marine Pollution Bulletin, 40, 968-980. http://dx.doi.org/10.1016/S0025-326X(00)00039-4

[4] Li, S.Y., Liu, G.X. and Miao, F.M. (1994) The Distribution and Environmental Background Values of the Heavy Metals in Sediment of the Bohai Sea. China Environmental Science, 14, 370-376.

[5] Chen, J.L., Liu, W.X. and Liu, S.Z. (2004) An Evalution on Heavy Metal Contamination in the Surface Sediments in Bohai Sea. Marine Sciences, 28, 16-21.

[6] Ye, S.Y. (2008) Geochemical Survey and Assessment Report of the Inshore Area of in Hebei Province. Qingdao Institute of Marine Geology, Qingdao.

[7] Luo, X.X., Zhang, R. and Yang, J.Q. (2010) Distribution and Pollution Assessment of Heavy Metals in Surface Sediment in Laizhou Bay. Ecology and Environmental Sciences, 19, 262-269. 